\title{
High precision surface protection of Al-based alloy parts using laser micro cladding
}

\author{
Yury A. Melnik ${ }^{1}$, Tatyana V. Tarasova ${ }^{1}$, Galina O. Gvozdeva ${ }^{1, a}$ and Steffen \\ NOWOTNY ${ }^{2}$ \\ 1 Moscow State University of Technology "STANKIN", 1 Vadkovsky per., 127994 Moscow GSP-4, Russian Federation \\ 2 Fraunhofer Institute for Material and Beam Technology (Fraunhofer IWS), 28 Winterbergstrasse 01277 Dresden, Germany
}

Received 3 October 2016, Accepted 28 November 2016

\begin{abstract}
Laser cladding is a well-known technique for wear protection coating tasks. Modern equipment for laser cladding enables material to be deposited with a lateral resolution of about $100 \mu \mathrm{m}$ and to produce high precision surface coating on small size parts. In this paper laser micro cladding process was investigated to produce wear protective coatings on Al-based alloy surface. Al-matrix composite (AlSi30) surface layers with thickness in the range 15-600 $\mu \mathrm{m}$ were formed on AlMgSi0,5 alloy surface by laser micro cladding. The influence of laser cladding parameters (powder mass flow, vertical increment etc.) and layers number on quality of the deposited coatings was investigated. The homogeneous and free of pores and cracks coating microstructure was produced. The influence of the laser cladding parameters and layers number on functional characteristics of the deposited coatings (e.g. hardness, abrasive wear resistance and electrical conductivity) was investigated. It was found that hardness and wear resistance of the coatings increased with the decrease of powder mass flow. The technological possibility of AlSi30 wear protective layers production on surface of AlMgSi0,5 alloy with roughness up to $R a 1,2 \mu \mathrm{m}$ and microhardness up to $300 \mathrm{HV}_{0,05}$ using laser micro cladding technology was demonstrated.
\end{abstract}

Key words: Laser micro cladding / surface protection / aluminium alloy / precise surface protection / electrical conductivity

\section{Introduction}

The laser cladding is a widely used technique for wear protection of metallic parts surface including Al-alloys [1]. Precision degree of this treatment (minimal coating array size, geometrical accuracy, surface coating roughness, thermal action on the parts) depends on the material deposition zone size (single clad track size). In the case of Al-based alloys the zone size is normally more than 1 mm. Modern laser cladding equipment allows to lessen this size down to $100 \mu \mathrm{m}[2,3]$. Thereupon laser micro cladding processes for Fe-, Ti-, Ni-, Co-alloys were developed [4-6]. However, some physical features of Al-alloys complicate the laser cladding downscale process of these materials.

The aim of present work is the investigation on laser micro cladding process of the Al-based alloys to determine the treatment parameters for high precision poreand crack-free coating deposition on the surface of smallsize Al-based alloys parts in order to improve their wear

a Corresponding author: gvozdeva_go@mail.ru resistance. Main objectives of this study are the investigation of coating and transition layer microstructure produced with variable cladding parameters, the investigation of laser micro cladding parameters influence on surface quality and functional characteristics of the deposited coatings (e.g. hardness, abrasive wear resistance and electrical conductivity).

\section{Experimental procedure}

The experiments on the micro cladding were carried out at the Fraunhofer Institute for Material and Beam Technology IWS (Dresden, Germany) using the setup shown in Figure 1. More details on the experimental setup can be found in Reference [7].

The setup included a 5-axes CNC-machine, a cwYb:YAG laser TruDISK 1000 (Trumpf, Germany) with $1 \mathrm{~kW}$ maximum output power and minimal laser spot size $62 \mu \mathrm{m}$ and the process head COAXpowerline (Fraunhofer IWS, Germany). The shielding and the carrier gas was Ar. The powder of AlSi30 alloy by TLS (TLS-Technik, 


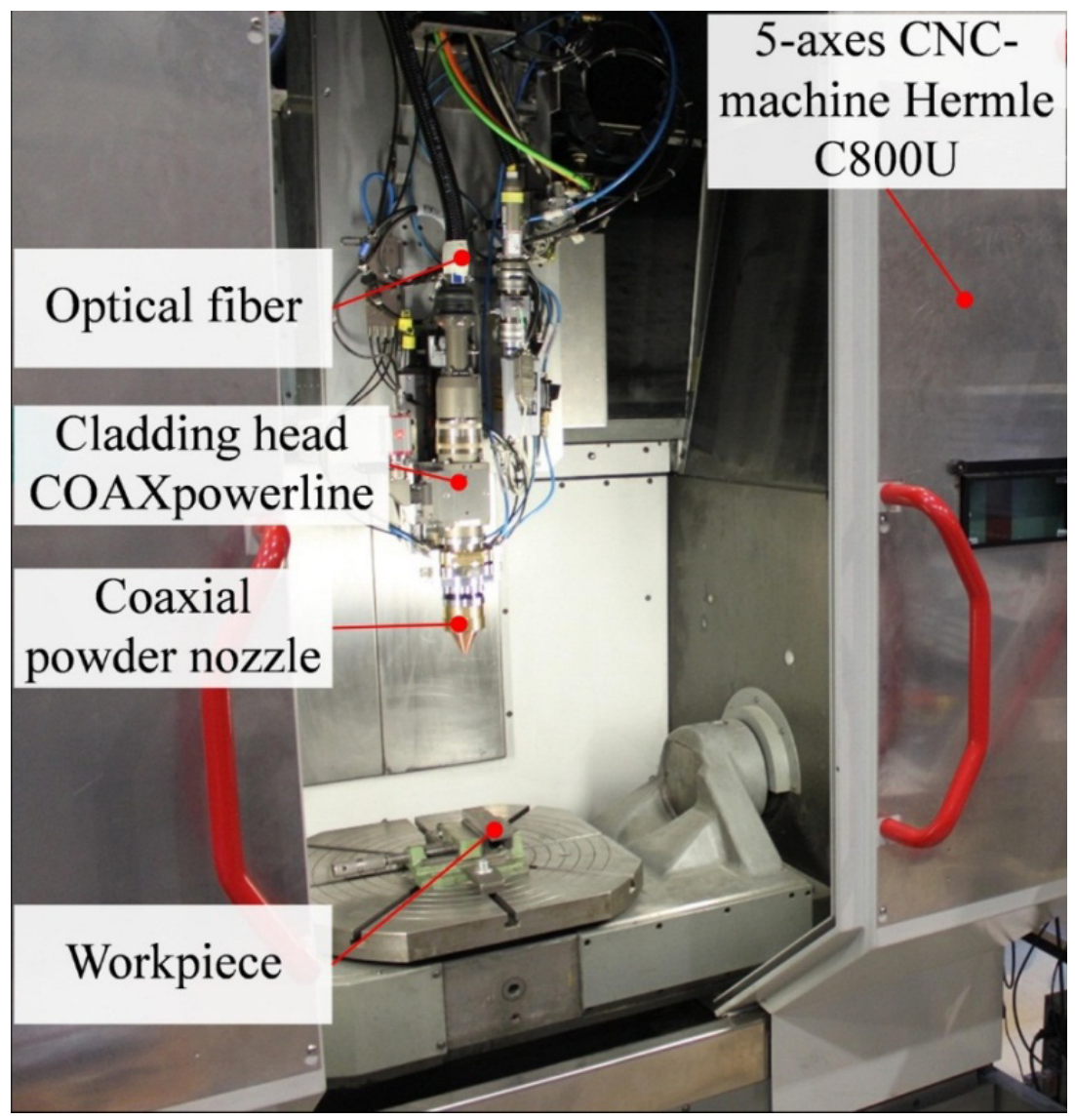

Fig. 1. Experimental setup for laser micro cladding.

Germany) with a $\mathrm{d}_{50}$-diameter [8] of $35 \mu \mathrm{m}$ was used (see Fig. 2). The composition of the powder is, $\%$ wt.: $29.5 \% \mathrm{Si}$; $\mathrm{Al}$ - in balance. The process head ensured a coaxial feeding of the powders with minimal spot size of about $0.8 \mathrm{~mm}$ at the workplane.

The coating was deposited by sequential overlapping of single tracks produced by linear movement of the cladding head in the $x$ - or $y$-direction (in plane). The overlapping ratio of the single tracks was set at the value of $50 \%$. The thickness of the coating was varied by the deposited layers number. Layers were deposited with different z-increment (out of plane). So that the chosen coordinate system is formed by directions of the laser scanning ( $x$ - and $y$-axes), the direction of the coating height $-z$ axis. Two deposition strategies were used: with 90 degree turning of the scanning direction between the associated layers (crosswise) and without turning (parallel) [9].

The transverse $(y-z$ and $x-z$ plane) cross-sections of the samples were produced after laser micro cladding was performed. The microstructure was investigated using optical microscope "Leica MEF4M" (Leica, Germany) and scanning electron microscope "VEGA 3 LM" (TESCAN, Czech Republic). The microhardness was measured by a microhardness tester "HP Mikromat" (Hegewald \& Peschke, Germany) under 0.5 N load for a dwell time of $10 \mathrm{~s}$. The microhardness measurements were performed on the transverse cross-sections.

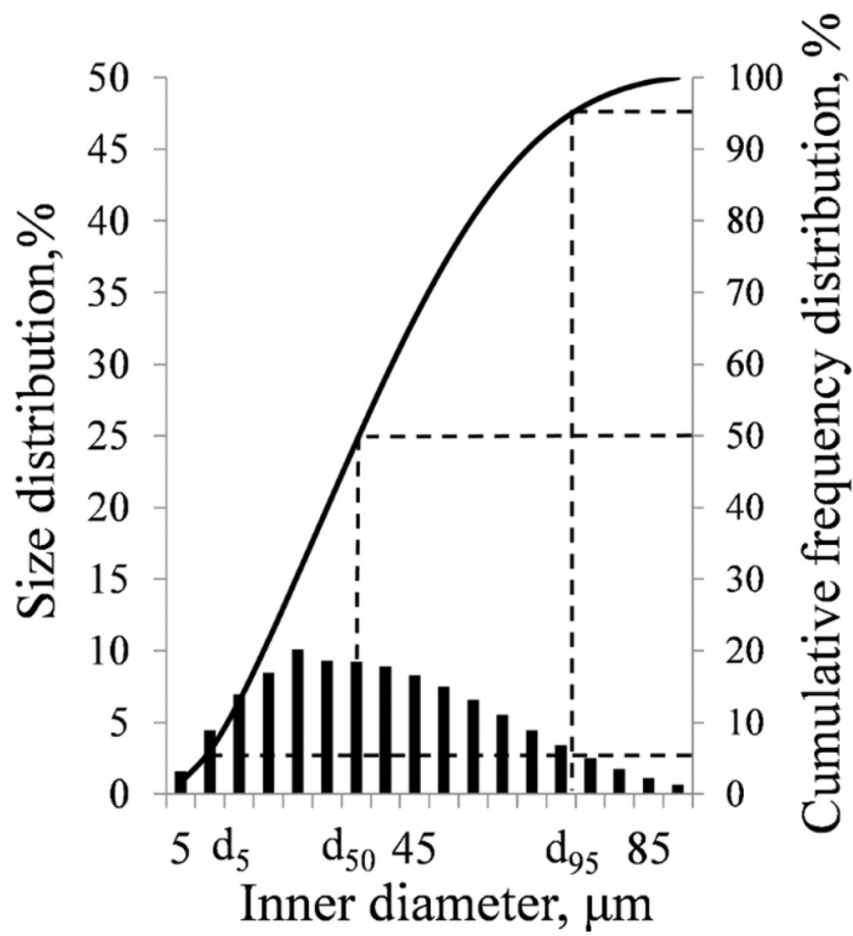

Fig. 2. Particle size distribution of used AlSi30 powder. 
Table 1. Laser micro cladding parameters sets.

\begin{tabular}{cccccc}
\hline $\begin{array}{c}\text { Parameters } \\
\text { set }\end{array}$ & $\begin{array}{c}\text { Powder mass } \\
\text { flow }\end{array} F_{\mathrm{P}}, \mathrm{g} / \mathrm{min}$ & $\mathrm{L}$ Laser power, Scanning speed, Z-increment, & \multicolumn{2}{c}{$\begin{array}{c}\text { Other } \\
\text { parameters }\end{array}$} \\
\hline Set 1 & 0.6 & 110 & 12 & 30 & Schielding gas flow $F_{\mathrm{S}}=5 \mathrm{l} / \mathrm{min}$ \\
Set 2 & 0.15 & 110 & 12 & 8 & $\begin{array}{c}\text { Carrier gas flow } F_{\mathrm{C}}=10 \mathrm{l} / \mathrm{min} \\
\text { Overlapping ratio } 50 \%\end{array}$ \\
& & & & Laser spot size at the workplane $d_{\mathrm{L}}=130 \mu \mathrm{m}$ \\
\hline
\end{tabular}

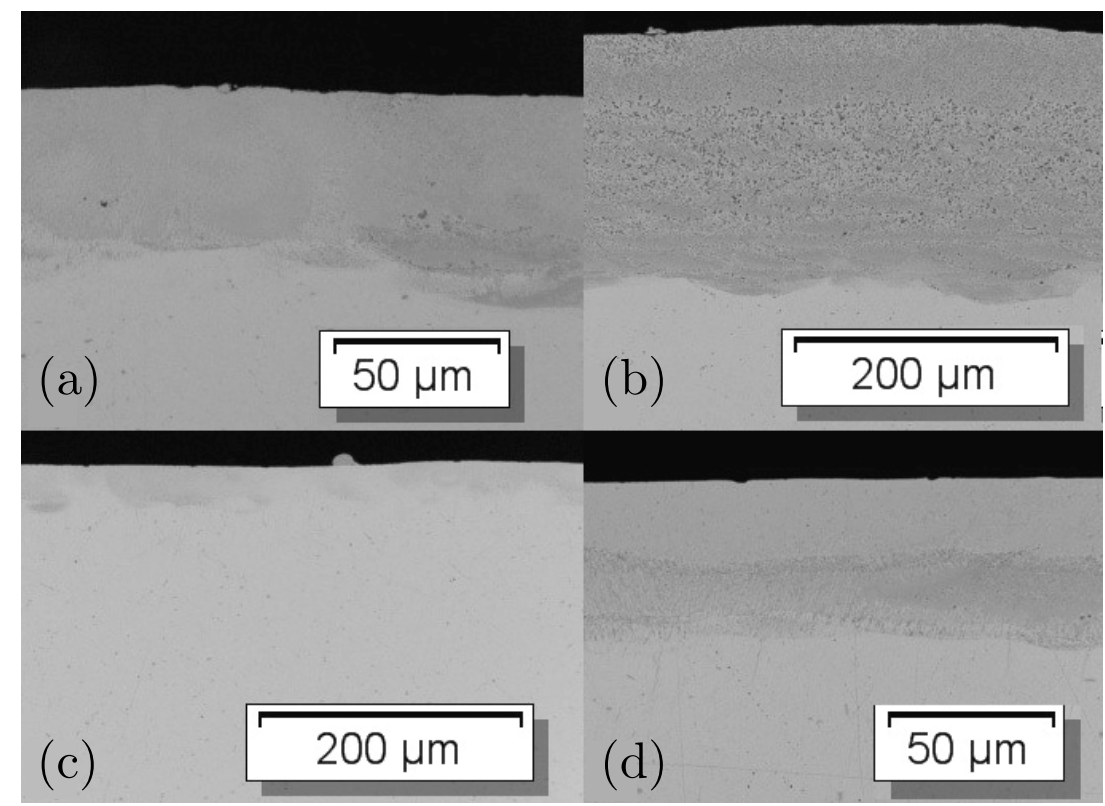

Fig. 3. Cross-sections of the coatings produced with various laser micro cladding parameters set and with various layers number: set $1-\mathrm{a}(\mathrm{N}=2$ layers $), \mathrm{b}(\mathrm{N}=8$ layers $)$, set $2-\mathrm{c}(\mathrm{N}=2$ layers $), \mathrm{d}(\mathrm{N}=8$ layers $)$.

The surface characteristics of the coated samples were investigated using a MarSurf XT 20 roughmeter and Keyence VHC-600 microscope.

The abrasive wear coefficients of the coatings were determined by ball-cratering method using a Calowear CSM testing machine (Anton Paar, Switzerland). The schema of the test can be found in Reference [10]. Abrasive slurry (an aqueous suspension of $3 \mu \mathrm{m} \mathrm{SiC}$ with an initial concentration of 0.75 g.cm ${ }^{-3}$ ) was inserted into the contact between a coated sample and the rotating counter body ball (steel 100Cr6; diameter 25.4 mm). Experimental conditions were: sliding distance $L=2800-3000 \mathrm{~m}$, normal load $F_{N}=0.24 \pm 0.01 \mathrm{~N}$. Testing with these conditions results in a spherically shaped wear scar on the sample surface. The depth of this wear scar characterizes the amount of the worn material $V$ is:

$$
V=\pi h^{2}(R-h / 3),
$$

The abrasive wear coefficient $k$ is, $\mathrm{mm}^{3} /(\mathrm{N} \times \mathrm{m})$

$$
k=\pi h^{2}(R-h / 3) /\left(L \times F_{N}\right),
$$

The depth of the wear scar was determined using a microscope MikroCAD (GFMesstechnik GmbH, Germany).

The electrical conductivity of the coating materials was investigated using the Sigmascope SMP10 (Fischer, Germany) instrument.

\section{Results and discussion}

During preliminary experiments two sets of laser micro cladding parameters were determined (further - Set 1 and Set 2). These sets are shown in Table 1.

The represented parameters sets allowed to produce fully dense and free of cracks or pores coatings with the high quality adhesion (see Fig. 3).

The represented parameters sets are different by the powder mass flow value - 0.6 g. $\mathrm{min}^{-1}$ (set 1) and 0.15 g. $\mathrm{min}^{-1}$ (set 2) - and by produced single track dimensions (width and height). The single track width that effect the minimal coating array size [11] was found $120 \mu \mathrm{m}$ for the set 1 and $100 \mu \mathrm{m}$ for the set 2 . It is in a good agreement with results obtained in previous studies [12]. The single track dimensions influence on the profile and on the roughness characteristics of the layer produced by single tracks overlapping [13]. It was confirmed by the results of the coating surface investigations conducted using a MarSurf XT 20 roughmeter and a Keyence VHC-600 3D microscope (see Figs. 4 and 5). To obtain required coating thickness a layer-by-layer deposition technique was used as described in the chapter 2 . Due to the different material deposition speed, the vertical $z$-increment value is different for the set $1(30 \mu \mathrm{m})$ and set $2(8 \mu \mathrm{m})$. The coating thickness was varied from circa $15 \mu \mathrm{m}$ up to circa $600 \mu \mathrm{m}$. It was found that the 


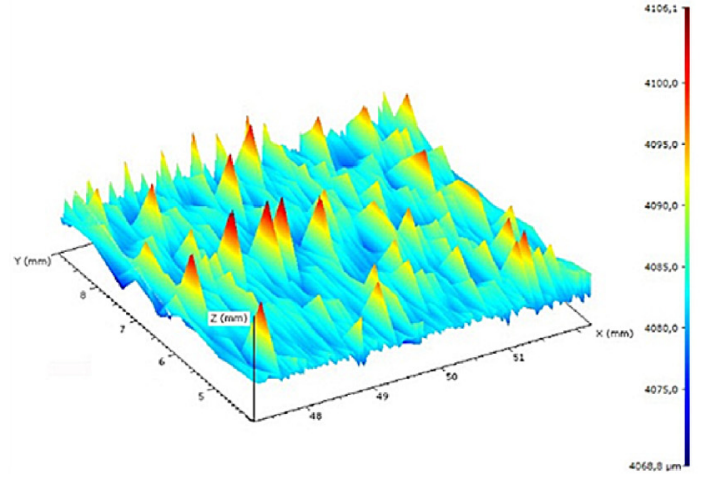

(a)

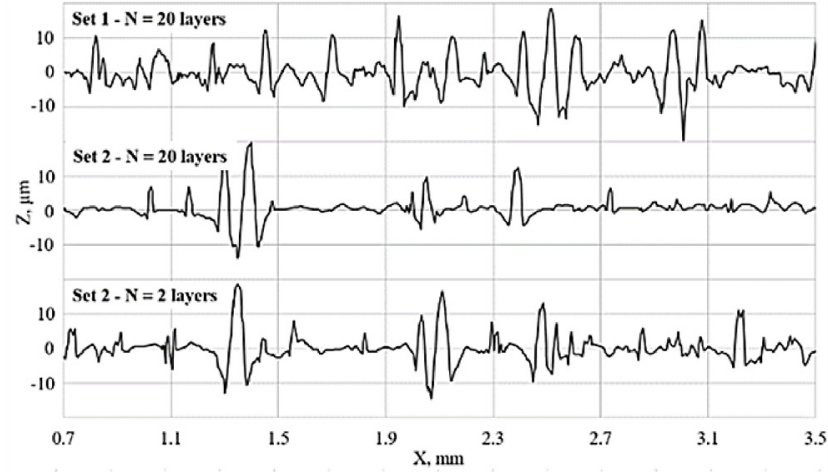

(b)

Fig. 4. Results of coating surface investigation obtained using a MarSurf XT 20 roughmeter, a - set 1 ; b - set 2 ((a) 3D image of an coating surface region; (b) surface roughness profiles showing the surface roughness of coating produced with various laser micro cladding parameters).

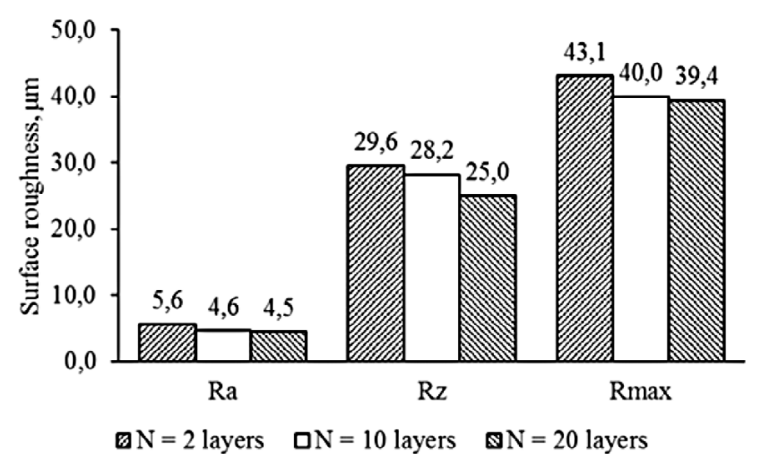

(a)

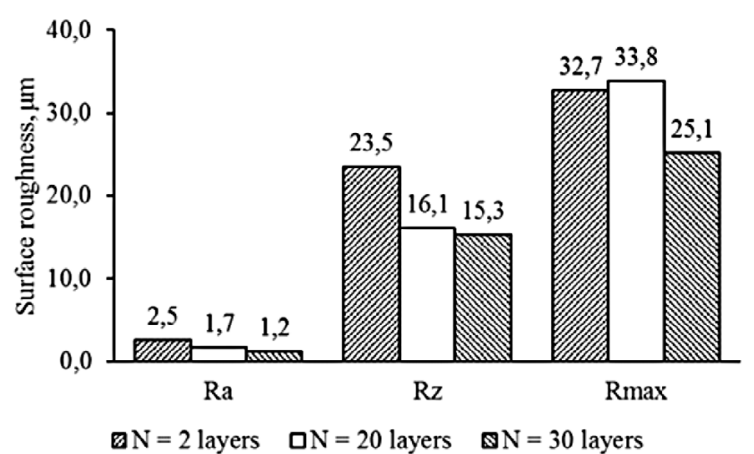

(b)

Fig. 5. Variations in surface roughness of the AlSi30 coating produced with various laser micro cladding parameters set and layers number.

powder mass flow increase from $0,15 \mathrm{~g} \cdot \mathrm{min}^{-1}$ (set 2) up to 0,6 g. $\mathrm{min}^{-1}$ (set 1) leads to the surface roughness increase (see Figs. 4 and 5).

The influence of layers number on the quality of the coatings surface was investigated. It was found that increase of the layers number leads to an asperities smoothing and to the surface quality improvement. The change of the surface roughness during the layer-by-layer coating deposition is shown in Figures 4 and 5 . It was found, that for set 1 all roughness parameters $\left(R a, R z, R_{\max }\right)$ were steadily decreasing with the layers number increase. In the case of set 2 the decrease of the $R a$ and $R z$ parameters with the layers number increase was detected. But the relation between $R_{\max }$ parameter and layers number was not observed. This fact can be explained by the following. The parameters $R a$ and $R z$ are integral (or average) characteristics. They describe the surface profile features due to the technological process of layer formation by the single track overlapping. The occurrence of these features is systematic (see Fig. 6).

But the $R_{\max }$ parameter characterizes the size of the local asperities. These asperities can be systematic (technological) as well as random (e.g. a result of powder drop adhesion on the coating surface). In the case of set 2 the single layer thickness $(8 \mu \mathrm{m})$ is more than 2 times smaller compared to the single layer thickness for set $1(30 \mu \mathrm{m})$ and it is smaller than powder particle size $(35 \mu \mathrm{m})$. So $R_{\text {max }}$ parameter is determined by the powder drop adhesion and it is not affected by the layers overlapping.

The influence of the deposition strategies (crosswise/parallel) on the quality of deposited coatings was investigated. It was found that the parallel deposition strategy did not ensure an equal surface roughness for different directions (see Tab. 2).

To improve the surface quality the laser glazing procedure was applied. It was shown that the surface roughness of the coated samples can be decreased more than two times using the laser glazing process from $R a 5.9 \mu \mathrm{m}$; $R z 29 \mu \mathrm{m} ; R_{\max } 42 \mu \mathrm{m}$ down to $R a 2.7 \mu \mathrm{m} ; R z 14 \mu \mathrm{m}$; $R_{\max } 26 \mu \mathrm{m}$, respectively (given for set 1 ). Optical images of the coating surface before and after laser glazing procedure are shown in Figure 7.

Coating structure. The influence of laser micro cladding parameters on the coating material structure was investigated in the previous paper [14]. The structure of the AlSi30 alloy produced by the laser micro cladding consists of the primary $\mathrm{Si}$ particles and solid solution $\mathrm{Al}(\mathrm{Si})$ (further $\alpha$-Al) and quasi-eutectic $(\mathrm{Si}+\alpha-\mathrm{Al})$. With 


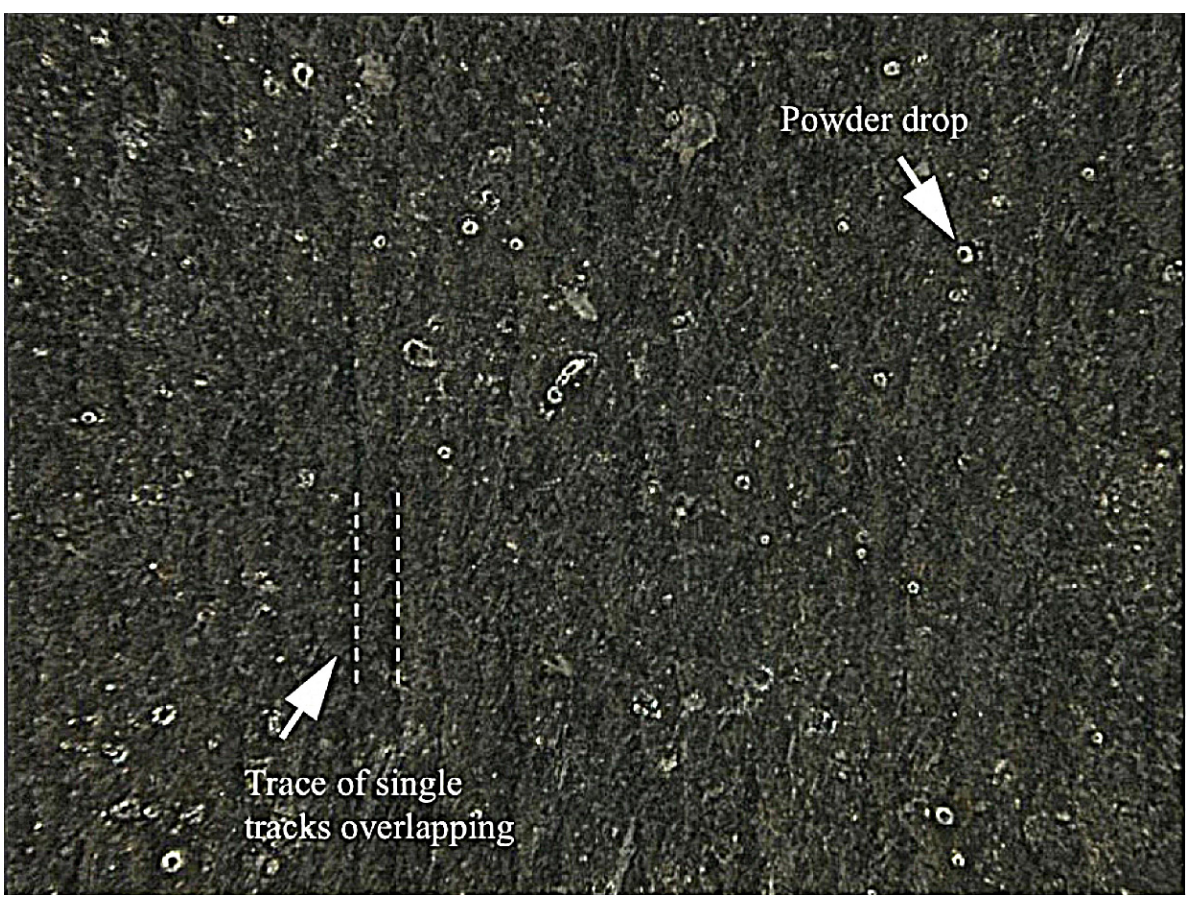

Fig. 6. Optical image of the coating surface "from above" showing powder drop adhesion on the coating surface and traces of the single track overlapping (laser micro cladding parameters set 2).

Table 2. Variations in surface roughness of the AlSi30 coating produced with various deposition strategies (given for set 2).

\begin{tabular}{|c|c|c|c|c|}
\hline \multicolumn{2}{|r|}{ Deposition strategy } & $R a, \mu \mathrm{m}$ & $R z, \mu \mathrm{m}$ & $R_{\max }, \mu \mathrm{m}$ \\
\hline \multirow{3}{*}{ Parallel } & Crosswise & $1.9 \pm 0.2$ & $13 \pm 2$ & $19 \pm 2$ \\
\hline & Along scanning direction & $1.7 \pm 0.25$ & $13 \pm 2$ & $19 \pm 2$ \\
\hline & Across scanning direction & $2.9 \pm 0.3$ & $19 \pm 2$ & $25 \pm 3$ \\
\hline
\end{tabular}
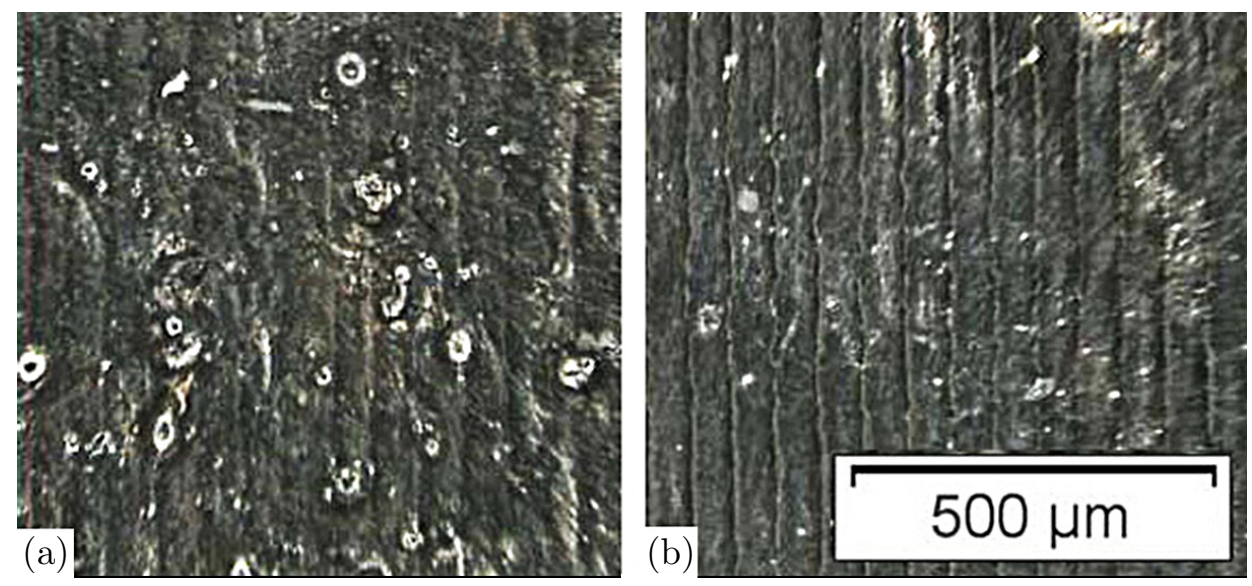

Fig. 7. Optical images of the coating surface before and after laser glazing procedure (laser micro cladding parameters set 1).

the powder mass flow decrease from 0.6 g.min ${ }^{-1}$ (set 1 ) down to 0.15 g.min ${ }^{-1}$ (set 2) structure dispersion degree and solubility of the Si in Al-lattice were found to increase, the Si particles volume in the coating structure was found to decrease. Moreover, it was shown that the annealing of the coated samples (set 2) in the air at the temperature $300{ }^{\circ} \mathrm{C}$ provided the $\alpha$-Al supersaturation decrease without Si particles size increasing. The differences of the AlSi30 alloy structures produced using var- ious laser micro cladding parameters are responsible for different material hardness, behavior under mechanical loading and other structure-sensitive functional characteristics. It was found that microhardness of the base material $(\mathrm{AlMgSi}, 5)$ was $80 \mathrm{HV}_{0,05}$. The hardness of the coating produced using laser micro cladding of AlSi30 powder on the AlMgSi0,5 sample was: $240 \mathrm{HV}_{0,05}$ (set 1); $300 \mathrm{HV}_{0,05}$ (set 2); $290 \mathrm{HV}_{0,05}$ (set $2+$ heat treatment). 

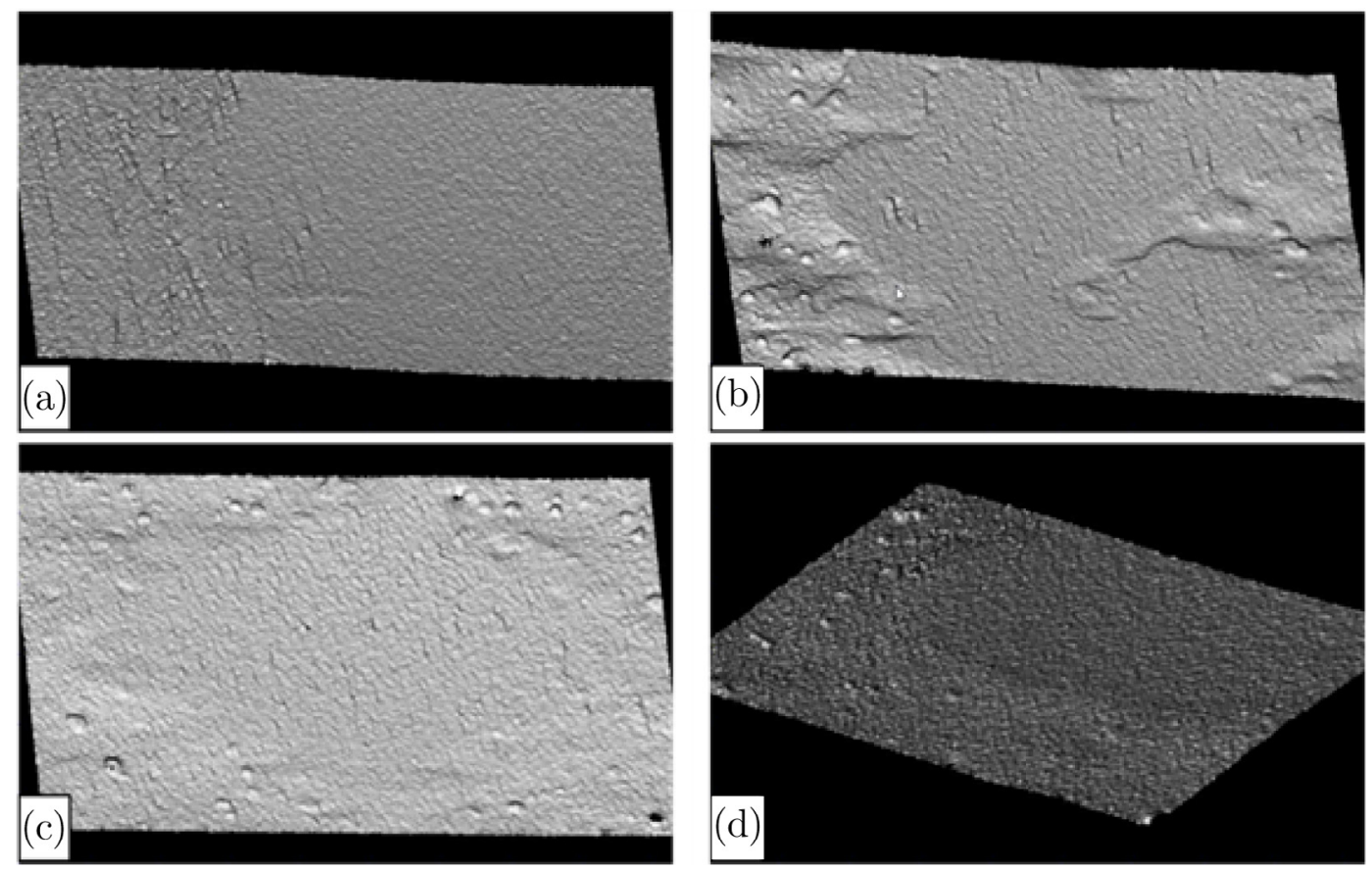

Fig. 8. The worn surface morphologies of the uncoated (a), coated (b-set 1, c - set 2), coated with the parameters set 2 and heat treated (d) samples at normal load of 0.,24 N, sliding distance 2800-3000 m under abrasive slurry medium of an aqueous suspension of $\mathrm{SiC}\left(3 \mu \mathrm{m} ; 0.75 \mathrm{~g} . \mathrm{cm}^{-3}\right)$ against steel ball; dimensions of the presented region $1.2 \mathrm{~mm} \times 1.8 \mathrm{~mm}$.

Abrasive wear. The abrasive wear behavior of the uncoated and coated samples and the coated samples after subsequent heat treatment was investigated. A significant increase of abrasive wear resistance of the coated samples compared to the uncoated samples was discovered. Moreover, a significant influence of laser micro cladding parameters on the abrasive wear behavior of the coating material was observed. The abrasive wear coefficient of the samples produced using set 2 $\left(k=1.8 \times 10^{-3} \mathrm{~mm}^{3} /(\mathrm{N} . \mathrm{m})\right)$ was 5 times lower compared to set 1 . It is significantly lower than the abrasive wear coefficient of the uncoated samples AlMgSi0.5 $\left(k=34.6 \times 10^{-3} \mathrm{~mm}^{3} /(\mathrm{N} . \mathrm{m})\right)$. It was found that the influence of subsequent heat treatment of the coated samples (annealing in the air at the temperature $300{ }^{\circ} \mathrm{C}$, $2 \mathrm{~h}$.) on the abrasive wear coefficient was not significant $\left(k=1.9 \times 10^{-3} \mathrm{~mm}^{3} /(\mathrm{N} . \mathrm{m})\right)$.

The worn surface morphologies of the uncoated, coated, coated and heat treated samples are presented in Figure 8. The deformed zones around the wear scars formed on the surface of the coated, coated and heat treated samples were found. The deformed zones around the wear scars on the uncoated AlMgSi0,5 sample surface was not seen. The deformed zone formation around the wear scars in the paper [15] was associated with a higher degree of the material crack toughness.

Electrical conductivity. The electrical conductivity of the uncoated, coated, coated and heat treated samples was investigated. It was shown that the electrical conductivity of the samples decreased by the AlSi30 coating deposition from $32.1 \pm 0.4 \mathrm{MS} / \mathrm{m}$ (for the uncoated sample $\mathrm{AlMgSi}, 5)$ down to $11.1 \pm 0.1 \mathrm{MS} / \mathrm{m}$ (set 1 ) and down to
$12.3 \pm 0.4 \mathrm{MS} / \mathrm{m}$ (set 2). It was found that the subsequent heat treatment of the coated samples (set 2) - annealing in the air at the temperature $300{ }^{\circ} \mathrm{C}, 2 \mathrm{~h}$. - leads to the electrical conductivity increase from $12.3 \pm 0.4 \mathrm{MS} / \mathrm{m}$ up to $15.2 \pm 0.4 \mathrm{MS} / \mathrm{m}$. The described electrical conductivity dependencies are in good agreement with the results of the coating structure investigations [14]. The electrical conductivity increase can be explained by: (a) decrease of Si particles volume in the coating structure associated with the powder mass flow decrease from $0.6 \mathrm{~g} . \mathrm{min}^{-1}$ (set 1) down to 0.5 g. $\mathrm{min}^{-1}$ (set 2); (b) the $\alpha$-Al supersaturation decrease as result of annealing of the coated sample.

\section{Conclusions}

The possibility of the wear resistance improvement of Al-based small-size parts by the precise surface layers deposition using laser micro cladding technology was demonstrated.

It was found that full dense crack-free AlSi30 surface layers with variable thickness in the range $15-600 \mu \mathrm{m}$ on the AlMgSi0,5 sample can be produced using laser micro cladding. The influence of laser micro cladding parameters on the surface quality was investigated. It was revealed that powder mass flow decrease in the range $0.6-$ 0.15 g. $\mathrm{min}^{-1}$ (from set 1 to set 2, respectively) leads to surface roughness decrease more than two times (down to $R a 1.2 \mu \mathrm{m})$.

It was shown that surface roughness during multilayer deposition decreased. Herewith for the laser micro cladding parameters set 1 all roughness parameters $(R a$, 
$\left.R z, R_{\max }\right)$ were found to be decreased with the layers number increase. For the set $2 R a$ and $R z$ parameters were found to be decreased with the layers number increase. This relation for the parameter $R_{\max }$ was not detected. The possibility of the surface quality improvement of the laser micro cladded AlSi30 coating using laser glazing procedure was demonstrated.

It was shown that AlSi30 coating deposition on the AlMgSi0,5 sample provided the microhardness increase from $80 \mathrm{HV}_{0,05}$ (base material) up to $300 \mathrm{HV}_{0,05}$ (AlSi30 coating, set 2 ). It was followed by the abrasive wear coefficient decrease from $34.6 \times 10^{-3} \mathrm{~mm}^{3} /($ N.m) down to $1.8 \times 10^{-3} \mathrm{~mm}^{3} /(\mathrm{N} . \mathrm{m})$.

It was shown that hardness of the coating material (AlSi30) can be varied in the range 240-300 $\mathrm{HV}_{0,05}$ depending on cladding and subsequent heat treatment parameters. The relation between abrasive wear behavior of the coating material and laser micro cladding parameters was found. It was shown that the powder mass flow decrease from 0.6 g. $\mathrm{min}^{-1}$ (set 1) down to 0.15 g.min ${ }^{-1}$ (set 2) was followed by hardness increase and by the decrease of abrasive wear coefficient.

It was found that the electrical conductivity of the uncoated AlMgSi0,5 sample $(32.1 \pm 0.4 \mathrm{MS} / \mathrm{m})$ can be decreased down to $11.1 \pm 0.1 \mathrm{MS} / \mathrm{m}$ by AlSi30 coating deposition using laser micro cladding technology. The electrical conductivity of coating material (AlSi30) can be varied in the range 11.1-15.2 MS/m depending on cladding and heat treatment parameters. The relation between electrical conductivity and coating structure was demonstrated.

Acknowledgements. This work was carried out with the financial support of the Ministry of Education and Science of Russian Federation in the framework of the state task in the field of scientific activity of MSTU "STANKIN" (No. 1059).

\section{References}

[1] St. Nowotny, S. Scharek, E. Beyer, K.-H. Richter, Laser Beam Build-Up Welding: Precision in Repair, Surface cladding, and Direct 3D Metal Deposition, J. Thermal Spray Technol 16 (2007) 344-348

[2] F. Brückner, St. Nowotny, M. Riede, F. Kubisch, Ch. Leyens, E. Beyer, Surface Functionalization by Highprecision Laser Cladding, Laser Technik J. 10 (2013) 2931

[3] J. Del Val, R. Comesana, F. Lusquinos, A. Riveiro, F. Quinter, J. Pou, Downscaling of conventional laser cladding technique to microengineering, Phys. Proc. 5 (2010) 341-348
[4] C. Meacock, A. Crespo, R. Vilar, Laser powder micro deposition of Ti6Al4V for the rapid manufacture of dental implants, in. P. J. Bartolo et al. (ed.), Proceedings of the 3rd international conference on advanced research in virtual and rapid prototyping, Leiria, Portugal, 2007, pp. 107-113

[5] S. Sankaré, Development of a rapid manufacturing process of titanium alloy mechanical parts by micro-laser cladding, Thèse, Université Strasbourg, 2007

[6] J. Del Val, R. Comesaña, F. Lusquiños, M. Boutinguiza, A. Riveiro, F. Quintero, J. Pou, Laser cladding of Cobased superalloy coatings: Comparative study between Nd:YAG laser and fibre laser, Surf. Coat. Technol. 204 (2010) 1957-1961

[7] S.N. Grigoriev, T.V. Tarasova, G.O. Gvozdeva, St. Nowotny, Solidification behaviour during laser microcladding of Al-Si alloys, Surf. Coat. Technol. 268 (2014) 303-309

[8] T.V. Tarasova, A.A. Filatova, K.E. Protasov, Methods for controlling particle size in corrosian resistant steel powders, in. A. Manzhirov and N. Gupta (ed.), Proceedings of the IUTAM Symposium on Growing solids Symposium Materials. IPMech RAS, Moscow, Russia, 2015, pp. 114-117

[9] S.N. Grigoriev , T.V. Tarasova, Possibilities of the Technology of Additive Production for Making ComplexShape Parts and Depositing Functional Coatings from Metallic Powders, Metal. Sci. Heat Treatment 57 (2016) $579-584$

[10] T.V. Tarasova, A.P. Nazarov, Yu. I. Shalapko, Abrasive and fretting wear resistance of refractory cobalt alloy specimens manufactured by the method of selective laser melting, J. Friction Wear 5 (2014) 365-373

[11] I. Yadroitsev, P. Bertrand, G. Antonenkova, S. Grigoriev, I. Smurov, Use of track/layer morphology to develop functional parts by selective laser melting, J. Laser Appl. 5 (2013) 052003

[12] S.N. Grigoriev, T.V. Tarasova, G.O. Gvozdeva, St. Nowotny, Microcladding of hypereutectic Al-Si alloys: technological aspects and structure features, Int. J. Cast Metals Res. 6 (2014) 357-361

[13] V. Ocelik, O. Nenadl, A. Palavra, J.Th.M. De Hosson, On the geometry of coating layers formed by overlap, Surf. Coat. Technol. 242 (2014) 54-61

[14] S.N. Grigoriev, T.V. Tarasova, G.O. Gvozdeva, St. Nowotny, Structure formation of hypereutectic Al-Sialloys produced by laser surface treatment, J. Mech. Eng. 6 (2013) 389-394

[15] E. Hornbogen, The role of the fracture toughness in the wear of metalls, Wear 33 (1975) 251-259 